\title{
Correction to: The Catalyst Sensitivity Index (CSI): A Framework and Metric to Assess the Impact of Catalyst Efficiency Enhancements upon Energy and $\mathrm{CO}_{2}$ Footprints
}

\author{
Tiancun Xiao ${ }^{1} \cdot$ Tara Shirvani $^{2,4} \cdot$ Oliver Inderwildi $^{2,5} \cdot$ Sergio Gonzalez-Cortes ${ }^{1} \cdot$ Hamid AIMegren $^{3} \cdot$ David King $^{2}$. \\ Peter P. Edwards ${ }^{1}$
}

Published online: 11 April 2019

(c) Springer Science+Business Media, LLC, part of Springer Nature 2019

\section{Correction to: Topics in Catalysis (2015) 58:682-695 https://doi.org/10.1007/s11244-015-0401-1}

The original version of the article unfortunately contained an error in article title. The authors would like to correct the error with this erratum. The corrected title is "The Catalyst Sensitivity Index (CSI): A Framework and Metric to Assess the Impact of Catalyst Efficiency Enhancements upon Energy and $\mathrm{CO}_{2}$ Footprints".

The original article can be found online at https://doi.org/10.1007/ s11244-015-0401-1.

Peter P. Edwards

peter.edwards@chem.ox.ac.uk

1 King Abdulaziz City of Science and Technology-Oxford Petrochemical Research Centre (KOPRC), Inorganic Chemistry Laboratory, University of Oxford, South Parks Road, Oxford OX1 3QR, UK

2 Smith School of Enterprise and the Environment, University of Oxford, Oxford OX1 3QY, UK

3 Material Research Institute, King Abdulaziz City for Science and Technology, PO Box 6086, Riyadh 11442, Kingdom of Saudi Arabia

4 Present Address: Energy and Transport Unit of the World Bank Group, 1818 H St. NW, Washington, DC 20433, USA

5 Present Address: World Economic Forum, 91-93 route de la Capite, Cologny, 1223 Geneva, Switzerland 